\section{Chemerin and Cardiovascular Risk in Rheumatoid Arthritis after Interleukin 6 Receptor Blockade}

To the Editor:

We read with great interest the recently published manuscript by Dessein, et $a l^{1}$ regarding chemerin concentrations and cardiovascular disease (CVD) risk in patients with rheumatoid arthritis (RA). The authors state in their discussion that "chemerin may contribute to the link between inflammation and increased risk of coronary artery disease among nonobese patients with RA. Indeed, systemic inflammation was strongly associated with chemerin concentrations in our analysis, and suppression of inflammation with adalimumab is linked to reduced chemerin concentrations in RA"2.

We would like to add to this statement the findings of our recently published study of anti-interleukin 6 receptor blockade with tocilizumab (TCZ) on chemerin serum levels, as well as its interrelated plasminogen activator inhibitor 1 (PAI-1) reductions, in 19 patients with RA ${ }^{3}$. We found that TCZ treatment for 6 months resulted in significant reductions in chemerin and PAI-1 levels in an interrelated manner, despite increasing adiposity. Specifically, chemerin and PAI-1 levels decreased significantly from baseline through 3 to 6 months (from $256 \pm 79$ to $174 \pm 12$ and 210 $\pm 85 \mathrm{ng} / \mathrm{ml}, \mathrm{p}=0.003$; from $73 \pm 27$ to $56 \pm 22$ and $51 \pm 28 \mathrm{pg} / \mathrm{ml}, \mathrm{p}=$ 0.029 , respectively), while the body mass index and waist circumference increased. In a multivariate model, chemerin decrease was significantly and independently associated with PAI-1 decrease at 6 months (standardized $\beta 0.430, p=0.024$ ). Interestingly, insulin resistance and sensitivity indices (HOMA-IR and Quicki Index) did not change in our study ${ }^{3}$.

Parallel to that, in an unpublished work, we also measured carotid-femoral pulse wave velocity (PWV) at baseline and at the completion of the 6-month TCZ treatment. Carotid-femoral PWV is considered the simplest, least invasive, strongest, and most reproducible method to determine arterial stiffness ${ }^{4}$, an indicator of arterial atherosclerosis. In a small sample of 10 patients, we found that carotid-femoral PWV decreased significantly (from $8.25 \pm 1.38$ to $6.96 \pm 0.97 \mathrm{~m} / \mathrm{s}, \mathrm{p}=$ 0.001 ) and that chemerin decrease was significantly correlated to carotid-femoral PWV decrease $(r=0.837, p=0.003)$, further suggesting that chemerin-mediated interactions are involved in the atherosclerotic process in these patients.

We concur with Dessein, et al that, although very indicative, it cannot yet be proven from the data available in the literature that chemerin is an unequivocal cardiovascular risk factor in patients with $\mathrm{RA}^{5}$, and that prospective studies are needed to fully determine the role of chemerin concentrations on cardiovascular risk stratification in RA. More importantly, from the clinical standpoint, the role of the various modalities of RA treatment on CVD risk, although promising, needs further investigation. The works by Dessein, et al and ourselves contribute to the current knowledge.

KONSTANTINOS MAKRILAKIS, MD, MPH, PhD; KALLIOPI FRAGIADAKI, MD; PETROS P. SFIKAKIS, MD, PhD; First Department of Propaedeutic/Internal Medicine, University of Athens Medical School, Laiko General Hospital, Athens, Greece; GEORGE D. KITAS, MD, PhD, Dudley Group National Health Institutes Foundation Trust, Dudley, and Arthritis Research UK Epidemiology Unit, University of Manchester, Manchester, UK. Address correspondence to Dr. K. Makrilakis, First Department of Propaedeutic/Internal Medicine, Athens University Medical School, Laiko General Hospital, 17 Ag. Thoma St., 11527 Athens, Greece. E-mail: kmakrila@med.uoa.gr

\section{REFERENCES}

1. Dessein PH, Tsang L, Woodiwiss AJ, Norton GR, Solomon A. Circulating concentrations of the novel adipokine chemerin are associated with cardiovascular disease risk in rheumatoid arthritis. J Rheumatol 2014;41:1746-54.

2. Herenius MM, Oliveira AS, Wijbrandts CA, Gerlag DM, Tak PP, Lebre MC. Anti-TNF therapy reduces serum levels of chemerin in rheumatoid arthritis: a new mechanism by which anti-TNF might reduce inflammation. PLoS One 2013;8:e57802.

3. Makrilakis K, Fragiadaki K, Smith J, Sfikakis PP, Kitas GD. Interrelated reduction of chemerin and plasminogen activator inhibitor-1 serum levels in rheumatoid arthritis after interleukin-6 receptor blockade. Clin Rheumatol 2014 June 10 (E-pub ahead of print).

4. Laurent S, Cockroft J, Van Bortel L, Boutouyrie P, Giannattasio C, Hayoz D, et al. Expert consensus document on arterial stiffness: methodological issues and clinical applications. Eur Heart J 2006;27:2588-605.

5. Lehrke M, Becker A, Greif M, Stark R, Laubender RP, von Ziegler $\mathrm{F}$, et al. Chemerin is associated with markers of inflammation and components of the metabolic syndrome but does not predict coronary atherosclerosis. Eur J Endocrinol 2009;161:339-44.

J Rheumatol 2015;42:2; doi:10.3899/jrheum.141115 